\title{
DESAFIOS E OPORTUNIDADES DA ERA DO CONHECIMENTO
}

\author{
Helena Maria Martins Lastres \\ Sarita Albagli \\ Cristina Lemos \\ LiZ-REJANE LEGEY
}

\begin{abstract}
Resumo: Este artigo discute a necessidade de identificar as principais características da era do conhecimento, assim como de monitorar e orientar as conseqüências das transformações associadas ao novo padrão de acumulação em difusão. Aponta-se para a urgência de desenhar novas políticas e instrumentos que minimizem os desafios e potencializem as oportunidades associadas à inserção de países como o Brasil na era do conhecimento.

Palavras-chave: era do conhecimento; políticas de desenvolvimento; Brasil.

Abstract: This article addresses the need to identify the main characteristics of the information age, as well as to monitor and guide the new standards for accumulating and disseminating knowledge. It further underscores the urgency of developing new policy tools to manage the challenges and enhance the opportunities associated with Brazil's entrance into the information age.

Key words: information age; development policies; Brazil.
\end{abstract}

$\Lambda$ passagem do milênio caracteriza-se pela alta intensidade de mudanças de relevante importância e impactos econômicos, políticos e sociais. Em épocas de transformações tão radicais e abrangentes como essa, caracterizada pela transição de uma era industrial para uma baseada no conhecimento, aumenta-se, em muito, o grau de indefinições e incertezas. Há, portanto, que se fazer esforço redobrado para, em primeiro lugar, identificar e entender esses novos desafios - o que exige o desenvolvimento de um novo quadro conceitual e analítico que permita captar, mensurar e avaliar os elementos que são determinantes de tais mudanças. ${ }^{1} \mathrm{E}$, em segundo lugar, é necessário um esforço para distinguir, entre as características e tendências emergentes, as que são mais duradouras das que são transitórias. Ou seja, lidar com a necessidade do que Milton Santos resumiu como distinguir o modo da moda.

O objetivo deste artigo é exatamente o de, sob esta orien- tação, discutir o conjunto de oportunidades e desafios que se colocam para países, regiões, setores, instituições e indivíduos associados à emergência e difusão de uma era, sociedade ou economia do conhecimento.

Em sua última parte o artigo volta-se para a discussão do caso brasileiro, reforçando o argumento sobre a im- portância de entender as especificidades da atual transição e os novos espaços que podem ser aproveitados, na perspectiva de um projeto de desenvolvimento nacional capaz de articular e mobilizar esforços, bem como superar problemas estruturais - sobretudo as desigualdades sociais e regionais - que representam importante obstáculos a seu desenvolvimento.

\section{NOVA BASE TECNO-PRODUTIVA INTENSIVA EM CONHECIMENTO}

No novo padrão técnico-econômico nota-se a crescente intensidade e complexidade dos conhecimentos desenvolvidos e a acelerada incorporação de conhecimentos nos bens e serviços produzidos e comercializados. Destaca-se, sobretudo, a maior velocidade, confiabilidade e baixo custo de transmissão, armazenamento e processamento de enormes quantidades de conhecimentos codificados e de outros tipos de informação. $\mathrm{O}$ avanço desse processo ocorre paripassu com o aumento das possibilidades de privatização e "comodificação" desses conhecimentos e informações.

Esse novo padrão de acumulação apresenta soluções para alguns dos problemas relacionados ao referido esgo- 
tamento do padrão anterior, abrindo novas possibilidades de retomada do crescimento. Notadamente, no novo padrão são oferecidas formas que possibilitam a continuidade da produção e do consumo em massa de novos bens e serviços, minimizando os aspectos relacionados à existência de espaços de armazenamento; ao consumo de insumos e materiais e energéticos não-renováveis; bem como ao descarte - também em massa - da produção e consumo e seus efeitos negativos sobre o meio ambiente.

Uma das características distintivas desse novo padrão é a tendência à desmaterialização. Isso é, à diminuição absoluta e relativa da importância da parte material usada na produção de bens e serviços. Um exemplo são os softwares, que podem ser desenvolvidos, produzidos, adquiridos, distribuídos, consumidos e descartados sem necessariamente envolver a criação de novas formas materiais.

As Tecnologias da Informação e Comunicação (TIC) exercem papel central como fatores de dinamismo do novo padrão, impulsionando um conjunto de inovações técnico-científicas, organizacionais, sociais e institucionais e gerando novas possibilidades de retorno econômico e social nas mais variadas atividades. Por isso são atualmente consideradas como as principais difusoras de progresso técnico. Sua importância no novo padrão torna a capacitação na produção e desenvolvimento das TIC um elemento estratégico das políticas de diferentes países.

De fato, as mudanças introduzidas pelo novo padrão de acumulação têm caráter bastante amplo, adotando novas práticas de produção, comercialização e consumo de bens e serviços, novos saberes e competências, novos aparatos e instrumentais científicos e produtivos. Tudo isso acompanhado de mudanças significativas nas formas de organização, gestão e de atuação de empresas e demais instituições encarregadas de atividades de ensino, pesquisa e desenvolvimento, promoção, financiamento, etc.

\section{A INOVAÇÃO COMO FATOR ESTRATÉGICO DE SOBREVIVÊNCIA E COMPETITIVIDADE}

Nesse novo contexto, a inovação - entendida em suas dimensões tecnológica, organizacional e institucional - assume importância ainda mais destacada. A intensificação dos processos de adoção, difusão de inovações e sua posterior superação, implica que o tempo necessário para lançar e comercializar novos produtos tem-se reduzido e que os ciclos de vida dos produtos e processos estão também menores. Tal percepção tem levado alguns autores a qualificar a nova economia como "economia da inovação perpétua".

A capacidade de gerar e absorver inovações é, portanto, vista como elemento-chave da competitividade dinâmica e sustentável. Incrementar o processo de inovação requer o acesso aos conhecimentos e a capacidade de apreendê-los, acumulá-los e usá-los. O caráter complexo e dinâmico dos novos conhecimentos requer ênfase especial no aprendizado permanente e interativo, como forma de indivíduos, empresas e demais instituições tornaremse aptos a enfrentar novos desafios e capacitarem-se para uma inserção mais positiva no novo cenário.

\section{NOVOS FORMATOS ORGANIZACIONAIS}

Os formatos organizacionais que estimulam os processos de aprendizagem coletiva, cooperação e dinâmica inovativa assumem importância ainda mais fundamental para o enfrentamento de novos desafios colocados pela difusão da era do conhecimento.

Por um lado, ressalta a tendência à maior integração das diferentes funções e unidades - pesquisa, produção, administração, marketing, etc. - de uma mesma organização. De outro, destacam-se os novos padrões de cooperação e competição entre os diversos agentes políticos, sociais e, sobretudo, econômicos, interligados em escala planetária. Os novos formatos organizacionais com base na interligação de empresas produtoras, fornecedoras, comercializadoras e prestadoras de serviços e delas com outras instituições, requerem também equipamentos e metodologias operacionais inovadores e, nesse sentido, são crescentemente dependentes tanto das TIC, como de informação e conhecimento.

Esses novos formatos organizacionais que privilegiam a interação e a atuação conjunta dos mais variados agentes - como redes, arranjos e sistemas produtivos e inovativos - vêm-se consolidando como os mais adequados para promover o aprendizado intensivo e a geração de conhecimento e inovações. Além disso, tais formatos detêm elevado potencial de ao mesmo tempo mobilizar e proteger as capacitações e, sobretudo, os conhecimentos tácitos acumulados.

Assim, considera-se que a competitividade de empresas e outras organizações depende crescentemente da amplitude das redes em que participam, bem como de seu uso. Isso é que justifica o fato de os novos empreendimentos instalados no mundo inteiro realizarem-se em bloco, sob a forma de arranjos produtivos, incluindo particularmente redes de for- 
necedores e de outros insumos e serviços estratégicos em torno dos empreendimentos-âncora.

A aglomeração de empresas e o aproveitamento das sinergias coletivas geradas por suas interações, e delas com o ambiente onde se localizam, vêm, de fato, fortalecendo suas chances de sobrevivência e crescimento, constituindo-se em importante fonte geradora de vantagens competitivas duradouras. A participação em tais formatos organizacionais é estratégica para empresas de todos os tamanhos, mas, em especial, empresas de pequeno porte, ajudando-as a superar barreiras em seu crescimento e a produzir e comercializar seus produtos em mercados nacionais e até internacionais. Arranjos produtivos locais que reunem empresas desse tipo são especialmente importantes em regiões pouco desenvolvidas e de baixo nível de emprego.

Há, no entanto, que se cuidar para que nessa tentativa perpétua de aumentar a competitividade siga-se uma trajetória que reforce a solidariedade entre agentes e regiões, em vez de a destroçar.

\section{SOCIEDADE DA INFORMAÇÃO E ACESSO AO CONHECIMENTO}

Países e blocos dedicam-se a traçar estratégias e a promover iniciativas orientadas para enfrentar os novos desafios e alcançar os benefícios que tem a oferecer a difusão das Tecnologias da Informação e Comunicação (TIC), assim como da própria sociedade da informação. No entanto, dar acesso a essas novas tecnologias e promover seu uso é essencial, mas ainda insuficiente. Mais grave do que não possuir acesso às novas tecnologias e às informações é não dispor de dados suficientes para desenvolver e produzir conhecimentos, que permitam dominar novas tecnologias e gerar conteúdos para novas redes eletrônicas.

Fala-se atualmente em era da ignorância (como o revés da era do conhecimento), chamando-se a atenção para os riscos associados à hiperinformação, resultante do alto volume de informação em circulação e ao relativo descuido com a geração e acumulação de conhecimentos.

Tais questões requerem uma reflexão cuidadosa com vista na definição de estratégias capazes de alavancar o desenvolvimento econômico, político e social. Por exemplo, o comércio eletrônico constitui-se em importante ferramenta de compra e venda entre empresas e entre elas e o consumidor final. Todavia, urge também explorar o potencial dessas novas tecnologias e sistemas como fer- ramentas que permitem ampliar e aprofundar outras formas mais pró-ativas de interação entre agentes.

É preciso, sobretudo, realizar esforços concentrados de pesquisa e desenvolvimento $(\mathrm{P} \& \mathrm{D})$ e criar competências nas diferentes etapas desde a concepção, desenvolvimento e produção até a comercialização de equipamentos e sistemas adequados a tais finalidades. Trata-se ainda de ser capaz de prover conteúdos próprios para as novas mídias e redes digitais, bem como de promover o aprendizado e a capacitação de trabalhadores, cidadãos, empresas e organizações para fazerem o melhor uso possível dessas tecnologias.

\section{NOVA CENTRALIDADE DO TRABALHO E DO APRENDIZADO}

A transformação da informação e do conhecimento em força produtiva determinante, de um lado, e a evidência de crescente informacionalização e desmaterialização das economias, de outro, indicam também modificação substantiva na forma e no conteúdo do trabalho, que assume caráter cada vez mais "informacional", com implicações significativas sobre o perfil do emprego.

No entanto, e contrariamente às teses que indicam que o trabalho, ou o trabalho vivo, já não se constitui em recurso produtivo fundamental, argumenta-se aqui que, na verdade, ele investe-se de uma centralidade ascendente na dinâmica econômica, produtiva e inovativa. O trabalho é cada vez mais intensivo em conhecimentos e informações. Nesse contexto, observa-se a tendência à automação crescente do trabalho menos especializado, com implicações significativas sobre o perfil do emprego e, conseqüentemente, sobre as necessidades de formação e capacitação.

Para acompanhar as rápidas mudanças em curso é de extrema relevância a aquisição de novas capacitações e conhecimentos, o que significa intensificar a capacidade de aprender e interagir. Para além de garantias de acesso ao emprego e viabilização de novas formas de consumo, o aprendizado continuado torna-se condição fundamental na era do conhecimento para a inserção dos indivíduos não só como trabalhadores e consumidores, mas como cidadãos.

\section{NOVO REGIME DE ACUMULAÇÃO DOMINADO PELAS FINANÇAS}

Talvez o desafio mais sério a uma inserção positiva na era do conhecimento refira-se à aceleração da transição 
para um regime de acumulação em que a lógica financeira orienta as mudanças técnicas, econômicas e sociais. Ao mesmo tempo é o setor financeiro no mundo inteiro aquele que mais amplo e intenso uso vem fazendo das TIC, até porque suas principais transações envolvem transferências não-materiais.

O novo regime emerge e encontra suporte institucional nas maiores e mais ricas economias. O domínio do capital financeiro, dos investidores institucionais, dos novos métodos de valorização do capital, da preferência por liquidez e do foco na lucratividade financeira de curto prazo vêm contribuindo para inviabilizar investimentos de alto risco, custo e maturação - como particularmente aqueles em ciência, tecnologia e inovação (CT\&I) e em formação e capacitação de recursos humanos.

Ao mesmo tempo, cresce a tendência à conformação de quadros macroeconômicos que desafiam, senão anulam, a possibilidade de implementar políticas nessas e outras áreas. A instabilidade e vulnerabilidade macroeconômicas - resultantes de déficits externos elevados e altas taxas de juros - representam importantes políticas "implícitas" que minam o investimento em capital real e intelectual de longo prazo.

\section{NOVA DIMENSÃO DO ESPAÇO}

Com a aceleração da globalização, o espaço geográfico também conquistou novos contornos, características e definições. As novas tecnologias e sistemas modificam a antiga trajetória da evolução territorial e introduzem novas lógicas.

Juntamente com o avanço da "desmaterialização" da economia, o desenvolvimento de novas formas de pagamento, a conformação de comunidades virtuais ativas, o desenvolvimento de novos sistemas informatizados em todos os campos de atividade - saúde, educação, segurança, entre outros - e da expansão de redes que operam em tempo real, assiste-se ao alargamento da importância do espaço informacional.

As tecnologias da informação e comunicação vêm revolucionando as relações espaço-temporais, assim como a aceleração da globalização torna mais sensíveis as especificidades e vantagens comparativas nacionais, regionais e locais. As diferenças entre os territórios constituem elemento básico no movimento de constante atualização dos termos que regem a divisão internacional do trabalho e a expansão dos mercados em escala global.

Desse modo, há uma revalorização da dimensão espacial e, particularmente do espaço local, à medida que se acentua a importância da diferenciação concreta entre os lugares.

O desafio é considerar essas duas dimensões do espaço - o virtual e o local - como complementares e igualmente relevantes no âmbito das novas políticas na era do conhecimento.

\section{GLOBALIZAÇÃO: CONVERGÊNCIAS E DIVERGÊNCIAS}

A difusão das tecnologias da informação propiciou os meios técnicos para que se articulem em tempo real organizações, indivíduos e instâncias geograficamente distantes. $\mathrm{O}$ advento e difusão do novo paradigma tecno-econômico, assim como a correlata aceleração do movimento de globalização, associam-se centralmente a mudanças político-institucionais originárias dos países mais desenvolvidos do mundo. Mudanças que induziram ao progressivo movimento de liberalização e desregulação dos mercados mundiais e, sobretudo, a desregulação dos sistemas financeiros e dos mercados de capitais. Isto tudo supostamente associado às crescentes exigências de maior competitividade tanto em nível nacional, quanto internacional por parte de países e empresas. Como uma decorrência, abrir, estabilizar, desregular e privatizar tornaramse as palavras de ordem no âmbito da maior parte das políticas macroeconômicas implementadas desde então.

No entanto, ao contrário de se caminhar em direção ao apregoado mundo sem fronteiras, global e homogêneo, com a aceleração da globalização, na verdade, assiste-se ao aprofundamento das diferenças entre diferentes países e regiões do planeta, em detrimento dos países que se situam na periferia do sistema de poder global. As análises sobre o atual processo de globalização geralmente não incluem duas grandes regiões do planeta, que juntas comportam mais de sessenta países, a África e a América Latina. O comércio mundial dessas regiões vem apresentando uma tendência decrescente, representando, em 1996, apenas 6\% do global. Estima-se, também, que empresas multinacionais participem em dois terços das trocas comerciais, com $40 \%$ do comércio mundial que é realizado internamente aos grupos multinacionais. Outros indicadores mostram-nos, por exemplo, que cerca de $80 \%$ de toda a produção mundial ainda são consumidos nos países em que são produzidos; e que a poupança doméstica financia $95 \%$ da formação de capital. Ressalta ainda como distorção talvez mais flagrante a constatação de aumento nas bar- 
reiras à mobilidade de pessoas, e especificamente trabalhadores.

As desigualdades nas condições de provisão, acesso e uso de novas tecnologias, sistemas e conteúdos podem até gerar novas e mais complexas disparidades entre indivíduos, empresas e organizações, regiões, países e blocos. Na sociedade e economia do conhecimento, mais sério que a divisão digital, entre os que possuem ou não acesso às novas tecnologias, é a divisão do aprendizado, pois isso pode contribuir para ampliar a polarização existente na distribuição de poder, riqueza e conhecimento, expandindo as disparidades entre e até mesmo dentro de países, regiões e sociedades. É fundamental, sobretudo, promover a capacidade de aprender e de gerar, absorver e acumular novos conhecimentos.

Por um lado, a globalização vem provocando, portanto, a polarização crescente entre blocos, países, regiões e grupos sociais. Por outro, tende-se a incorporar, nesse processo, aos mercados dos que se situam em posição mais estratégica no cenário mundial, seja por seu poderio político-econômico-militar, seja no caso de alguns países em que a periferia é menos desenvolvida - porque adota normas trabalhistas, ambientais, tributárias, entre outras, consideradas como mais "flexíveis" ou "competitivas", e, portanto, mais "atrativas" para os grandes capitais internacionalizados.

\section{NOVAS HIERARQUIAS GEOPOLÍTICAS}

A reorganização espacial da atividade econômica direciona a uma clara re-hierarquização de seus centros decisórios. Observa-se a tendência ao reforço do denominado policentrismo econômico tripolar (países da Europa Ocidental, Japão e EUA), e, sobretudo, da posição hegemônica dos EUA. Estabelecem-se igualmente novas hierarquias geopolíticas, com base em novos diferenciais socioespaciais, e que refletem fundamentalmente as desiguais disponibilidades de informações e conhecimentos estratégicos e estabelecem claras linhas divisórias entre os que estão capacitados a promover ou a participar ativamente em uma dinâmica ininterrupta de inovação e aprendizado, e os que tendem a ser deslocados e subordinados.

É preciso superar a nova divisão internacional do trabalho, em que países e regiões desenvolvidos tendem a especializar-se na criação e comercialização de projetos, produtos e conteúdos, enquanto países e regiões menos desenvolvidos restringem seu papel ao de consumidores de equipamentos, tecnologias e conteúdos, quando muito se dedicando à manufatura de produtos com base em tecnologias já maduras, projetados nos países centrais.

\section{NOVO PAPEL DO ESTADO ANTE A GLOBALIZAÇÃO}

Com a aceleração da globalização, os Estados-Nações são desafiados em sua soberania como locus de hegemonia, diante da projeção de novos atores no cenário mundial blocos regionais, organismos multilaterais e, particularmente, os grandes grupos financeiros e multinacionais.

A pretensa necessidade de retração do Estado não encontra, porém, correspondência alguma nos países centrais. Apesar de o espaço e condições diferenciarem-se do passado, os governos dos países desenvolvidos vêm mantendo sua legitimidade e capacidade de intervir pro-ativamente. Observa-se, na verdade, a implementação de ampla gama de instrumentos cada vez mais complexos (e muitas vezes ainda invisíveis) como forma de contrabalançar os efeitos do grau elevado de exposição das economias ao novo ambiente externo.

Desse modo, embora a globalização implique maior condicionamento externo das políticas econômicas nacionais e, portanto, menor grau de liberdade dos governos nacionais - em particular em face da acelerada globalização financeira ocorrida no último quartel do século XX -, agora, mais do que nunca, impõe-se a necessidade de novas estratégias e políticas.

Em vez de perderem sentido, na verdade, as políticas nacionais passam a ter seu alcance, desenho, objetivos e instrumentos reformulados, visando ao atendimento de novos requisitos da era do conhecimento. Sobretudo no caso de economias em desenvolvimento, políticas nacionais de promoção da capacitação e do desenvolvimento econômico e social são condição indispensável a inserção menos subordinada no cenário internacional.

\section{SISTEMAS INOVATIVOS LOCAIS VERSUS TECNO-GLOBALISMO}

Contrariamente à visão sobre pretensa internacionalização dos esforços e resultados do desenvolvimento científico e tecnológico, observa-se uma concentração nitidamente nacional de tais atividades, com articulações sendo efetuadas quase exclusivamente entre os países e empresas tecnologicamente mais avançados. $\mathrm{Ou}$ seja, a geração e difusão de conhecimentos e de inova- 
ções representa exatamente um dos casos de não-globalização, contrariamente ao que se denomina de tecno-globalismo.

Se os progressos no campo das tecnologias da informação e comunicação abrem novas possibilidades de codificação e difusão de informações e conhecimentos os conhecimentos tácitos, que são enraizados em indivíduos, instituições e ambientes locais, logo difíceis (senão impossíveis) de serem transferidos -, permanecem de grande importância estratégica na era do conhecimento.

Longe, portanto, de significar um mundo integrado e sem fronteiras, no qual o conhecimento flui livremente, a nova ordem mundial exige níveis de qualificação e capacitação locais ainda mais elevados do que no passado.

\section{A URGÊNCIA DE UM DESENVOLVIMENTO SUSTENTÁVEL}

A passagem de um padrão técnico-econômico intensivo em recursos naturais para o atual, com base na utilização crescente de conhecimento e informação, impediu uma aceleração da crise, mas não reduziu as pressões sobre o meio ambiente. A sustentabilidade dos modelos de desenvolvimento coloca-se hoje como um dos mais sérios desafios da humanidade, o que requer novas orientações para esforços de crescimento econômico e de avanço do conhecimento científico-tecnológico, subordinando-as a princípios de inclusão, eqüidade e coesão social, de sustentabilidade ambiental e de caráter ético.

A proteção do capital natural, por sua vez, adquire nova relevância estratégica, não apenas por sua importância para o equilíbrio ecológico planetário, mas também como matéria-prima para as tecnologias avançadas. Este é o caso da biodiversidade, que apresenta amplo potencial para países ricos nesses recursos. No caso do Brasil, primeiro país em megadiversidade em nível mundial, ela pode vir a tornar-se uma vantagem comparativa do país no âmbito da geopolítica global, considerando sua ampla disponibilidade de recursos biogenéticos, a tradição de sua ciência na área biológica, além do acervo de conhecimentos tradicionais acumulados pelas populações locais e pertinentes para o acesso e as aplicações dessa biodiversidade.

No entanto, a importância ecológica e econômica das reservas biogenéticas existentes no país só farão da biodiversidade uma questão de fato estratégica para nós, caso o país capacite-se a destacar-se nessa área, tratandoa não como ônus, mas como oportunidade. Para isso, no entanto, o Estado brasileiro traz como desafio tratar de forma integrada as questões políticas, econômicas, ambientais, científico-tecnológicas e sociais em uma estratégia mais ampla de desenvolvimento nacional e das diferentes regiões ricas em biodiversidade.

\section{DESAFIOS PARA O BRASIL}

Para lidar com as profundas mudanças vividas na transição do milênio, colocam-se novas exigências quanto ao papel dos distintos agentes econômicos, governamentais e da sociedade em geral, bem como apresentam-se novas demandas para políticas e instrumentos de regulação, tanto públicos, como privados.

É premente a formulação de novas estratégias e alternativas de desenvolvimento, em níveis mundial, nacional e local, para trabalhar com os desafios sugeridos, exigindo novos modelos e instrumentos institucionais, normativos e reguladores que sejam capazes de solucionar questões que se apresentam diante da emergência da era do conhecimento e do padrão de acumulação dominado pelas finanças. Deve-se considerar também as mudanças associadas aos novos mecanismos de governança em nível mundial, que incluem as condições estabelecidas pela Organização Mundial do Comércio (OMC) e outras instituições e agências internacionais.

O Brasil dispõe de importantes potencialidades para capitalizar em seu favor, sobretudo por meio da correta identificação e aproveitamento de novos espaços que se abrem nesse período de transformações. Para tanto, deve ser capaz de articular e mobilizar forças em torno de um projeto nacional, bem como superar seus problemas estruturais - sobretudo as desigualdades sociais e regionais - que representam um pesado obstáculo a seu desenvolvimento.

Acima de tudo, recomenda-se a definição e implementação de novo projeto de desenvolvimento que reforce mutuamente a articulação entre política macroeconômica e política de desenvolvimento social, produtivo e, particularmente, de ciência, tecnologia e inovação, para uma inserção mais competitiva e autônoma, que assegure a coexistência entre o avanço do processo de globalização e a construção de bases produtivas modernas e dinâmicas e fortalecimento do capital social.

Aponta-se, particularmente, para a necessidade de estabelecer instrumentos financeiros que reduzam o impacto negativo de políticas macroeconômicas, em particular, das altas taxas de juros, para permitir (em vez de anular) a implementação dessas políticas. Indica-se, portanto, ur- 
gente implementação de uma estratégia de transição em direção a uma articulação benigna entre política macroeconômica e construção de uma rota de desenvolvimento sustentado.

\section{NOTAS}

Uma versão preliminar deste trabalho foi apresentada na Reunião Regional Sudeste - Rio de Janeiro e Minas Gerais - da Conferência Nacional de Ciência, Tecnologia e Inovação, Rio de Janeiro, 16 e 17 de agosto de 2001.

1. Um dos exemplos de destaque refere-se à suposta invisibilidade de novas formas de pagamento pelo uso de serviços de acesso à Internet denominados "gratuitos". Para detalhes, ver, entre outros, Lastres e Albagli, 1999.

\section{REFERÊNCIAS BIBLIOGRÁFICAS}

ALBAGLI, S. Geopolitica da biodiversidade. Brasília, Edições Ibama, 1998.

. "Globalização e espacialidade: o novo papel do local". In: CASSIOLATO, J.E. e LASTRES, H.M.M. (eds.). Globalização e inovação localizada: experiências de sistemas locais no Mercosul. Brasília, IBICT, 1999, p.181-99.

CASSIOLATO, J.E. e LASTRES, H.M.M. Globalização e inovação localizada: experiências de sistemas locais no Mercosul. Brasília, IBICT, 1999

FURTADO, C. O capitalismo global. São Paulo, Paz e Terra, 1998.

LASTRES, H.M.M. "Ciência e tecnologia na era do conhecimento: um óbvio papel?" Parcerias Estratégicas. Centro de Gestão Estratégica, n.9, out. 2000.

LASTRES, H.M.M. e ALBAGLI, S. Informação e globalização na era do conhecimento. Rio de Janeiro, Campus, 1999.
LEGEY, L-R. "A dinâmica e o ambiente de comércio eletrônico". In: PEREIRA, M.F. e PINHEIRO, L.V. (orgs.). O sonho de Otlet: aventura em tecnologia de informação e comunicação. Rio de Janeiro, IBICT, 2000.

LEGEY, L-R e ALBAGLI, S. "Construindo a sociedade da informação no Brasil: uma nova agenda". DataGramaZero - Revista de Ciência da Informação, v.1, n.5, out. 2000. Disponível em: <http:/ /www.dgz.org.br>.

LEMOS, C. "Inovação na era do conhecimento". In: LASTRES, H.M.M. e ALBAGLI, S. (orgs.). Informação e globalização na era do conhecimento. Rio de Janeiro, Campus, 1999. Reproduzido em Revista Parcerias Estratégicas. Brasília, Centro de Estudos Estratégicos, n.8, p.157-79, maio 2000.

. Redes para inovação - estudo de caso de rede regional no Brasil. Dissertação de Mestrado. Rio de Janeiro, COPPE/UFRJ, 1996.

SANTOS, M. Por uma outra globalização: do pensamento único à consciência universal. Rio de Janeiro, Record, 2001. 1991

Metamorfose do espaço habitado. São Paulo, Hucitec,

TAVARES, M.C e FIORI, J.L. Desajuste global e modernização conservadora. Rio de Janeiro, Paz e Terra, 1993.

Helena Maria Martins Lastres: Economista, Professora e Pesquisadora do Grupo de Inovação do Instituto de Economia da UFRJ (hlastres@ie.ufrj.br).

Sarita Albagli: Socióloga, Professora do Programa de Pós-Graduação em Ciência da Informação da UFRJ/ECO - MCT/IBICT (albagli@dep.ibict.br).

Cristina Lemos: Economista, Pesquisadora do Instituto Nacional de Tecnologia (INT/MCT) e do Instituto de Economia da UFRJ (cristina@int.gov.br).

Liz-Rejane Legey: Economista, Pesquisadora do MCT, Professora do Programa de Pós-Graduação em Ciência da Informação da UFRJ/ECO -MCT/IBICT (1legey@rjnet.com.br). 